\title{
The clinical burden of malaria in Nairobi: a historical review and contemporary audit
}

\author{
Sandra A Mudhune ${ }^{1}$, Emelda A Okiro ${ }^{1,2}$, Abdisalan M Noor ${ }^{1,2}$, Dejan Zurovac ${ }^{1,2}$, Elizabeth Juma ${ }^{3}$, Sam A Ochola ${ }^{4}$ \\ and Robert W Snow ${ }^{1,2^{*}}$
}

\begin{abstract}
Background: Widespread urbanization over the next 20 years has the potential to drastically change the risk of malaria within Africa. The burden of the disease, its management, risk factors and appropriateness of targeted intervention across varied urban environments in Africa remain largely undefined. This paper presents a combined historical and contemporary review of the clinical burden of malaria within one of Africa's largest urban settlements, Nairobi, Kenya.

Methods: A review of historical reported malaria case burdens since 1911 within Nairobi was undertaken using archived government and city council reports. Contemporary information on out-patient case burdens due to malaria were assembled from the National Health Management and Information System (HMIS). Finally, an audit of 22 randomly selected health facilities within Nairobi was undertaken covering 12 months 2009-2010. The audit included interviews with health workers, and a checklist of commodities and guidelines necessary to diagnose, treat and record malaria.
\end{abstract}

Results: From the 1930's through to the mid-1960's malaria incidence declined coincidental with rapid population growth. During this period malaria notification and prevention were a priority for the city council. From 2001-2008 reporting systems for malaria were inadequate to define the extent or distribution of malaria risk within Nairobi. A more detailed facility review suggests, however that malaria remains a common diagnosis ( $11 \%$ of all paediatric diagnoses made) and where laboratories $(n=15)$ exist slide positivity rates are on average $15 \%$. Information on the quality of diagnosis, slide reading and whether those reported as positive were imported infections was not established. The facilities and health workers included in this study were not universally prepared to treat malaria according to national guidelines or identify foci of risks due to shortages of national first-line drugs, inadequate record keeping and a view among some health workers (17\%) that slide negative patients could still have malaria.

Conclusion: Combined with historical evidence there is a strong suggestion that very low risks of locally acquired malaria exist today within Nairobi's city limits and this requires further investigation. To be prepared for effective prevention and case-management of malaria among a diverse, mobile population in Nairobi requires a major paradigm shift and investment in improved quality of malaria diagnosis and case management, health system strengthening and case reporting.

\footnotetext{
* Correspondence: rsnow@nairobi.kemri-wellcome.org

${ }^{1}$ Malaria Public Health \& Epidemiology Group, Centre for Geographic

Medicine Research - Coast, Kenya Medical Research Institute/Wellcome Trust

Research Programme, P.O. Box 43640, 00100 GPO, Nairobi, Kenya

Full list of author information is available at the end of the article
} 


\section{Background}

The intensity of malaria transmission in urban settlements of Africa is often considerably lower than the immediate peri-urban and rural surrounds [1-7] and driven largely by the presence of focal breeding sites developed for water storage or urban agriculture [8-12]. However, despite much reduced risks of acquiring malaria infections the diagnosis of clinical malaria in urban, low transmission areas remains common [13-16]. Rapid assessments of the malaria situation in four cities: Dar es Salaam, Tanzania [17], Abidjan, Cote D'Ivoire [18], Cotonou, Benin [19] and Ouagadougou, Burkina Faso [20] have highlighted the high rate of over-diagnosis of malaria among febrile patients attending clinics; the focal nature of infection risks associated with seasonal agricultural activities; and the inadequacies of routine medical statistics that should provide a realistic surveillance of malaria risks in these urban areas of subSaharan Africa. The authors conclude that the extent, risk factors, disease burden and appropriateness of targeted interventions in urban areas of Africa remains unknown.

Africa is expected to experience rapid rates of urbanization with $54 \%$ of Africans living in urban areas by 2030 [21]. This has the potential to radically change the landscape of malaria risk on the continent [22]. It is increasingly recognized that presumptive treatment of malaria in areas of Africa under declining transmission intensity is increasingly inappropriate [23], may increase patients risks of severe outcomes from un-diagnosed conditions [24] and increase unnecessary expense on limited public sector drug budgets or patients who have to pay for medicines. A multi-sectoral technical consultation on urban malaria in 2004 led to the Pretoria Statement, that stated the need to improve our understanding of the malaria risk extent, burden, diagnosis and targeted drug delivery in urban settings [6]. Unfortunately, the reliability and completeness of routine health statistics in many African urban settings remains poor [13].

The city of Nairobi, Kenya has an interesting malaria history and the extent of locally acquired transmission has not been formally defined for over 50 years. Nairobi is located $1,795 \mathrm{~m}$ above sea level with a temperate climate and low temperatures (that can drop to $10^{\circ} \mathrm{C}$ in June/July), representing sub-optimal conditions for sporogony in the Anopheles [25]. The cold seasonal temperature in Nairobi is thought to limit the development of the Plasmodium falciparum sporozoite stage in the salivary glands of the mosquito vector; however windows of transmission potential do exist within an average year and vary between years. The temperature limiting effects of transmission in Nairobi have largely underpinned the recent controversy on the likelihood of transmission of malaria within Nairobi and whether clinical malaria can be acquired within the city limits [26-30]. In an effort to improve the understanding of the malaria burden in Nairobi, this paper combines historical evidence of the reported clinical burden of malaria from the early 1900's as it grew in size to the present day and a contemporary audit of diagnoses made at government supported clinics across the city in 2010 to augment inadequate information systems reported data.

\section{Methods}

\section{Review of historical malaria case reports and recent health information system data}

Reports of malaria cases since 1911 were reviewed from annual medical reports, authored by the Director of Medical Services for the Colony and Protectorate of Nairobi (1908-1964; missing 1909, 1911-1915) and the Medical Officer of Health, for the Nairobi Municipality (1930-1964; missing 1940-1945) retrieved from the Kenya National Archives Library, the Ministry of Health Library and the Macmillan Memorial Library in Nairobi. These extracted data were assembled to define reported malaria cases and triangulated with other published sources that described the various epidemics. Contemporary information on out-patient case burdens due to malaria were assembled from annual reports from the Ministry of Health's National Health Management and Information System (HMIS). Data are compiled by the health service information subsystem and are routinely collected through a network of facility units distributed throughout the country [31-34].

\section{Health facility audit 2010}

A database of geo-located health facilities in Kenya [35] was used to identify all out-patient service providers in Nairobi that are supported by the Ministry for Medical Services (MoMS) or managed by the Local Authority (LA) and provide general out-patient care, i.e. are not specialist centres for $\mathrm{TB}$, mental health or reproductive health or attached to district or tertiary referral hospitals. Of the universe of 52 MoMS or LA primary-level out-patient providers, 22 were randomly selected to form the basis of the present study (Figure 1). Survey tools were adapted from those used in Kenya to define the quality of malaria case-management [36,37] and included: a) facility audit of available drugs, diagnostics, malaria guidelines and job aides, record keeping materials, weighing scales and other supporting commodities; b) interview schedule with health workers performing case-management on the day of the survey to determine health workers' demographics, exposure to training in malaria diagnosis and treatment and knowledge of standard recommended treatment protocols; and c) review 


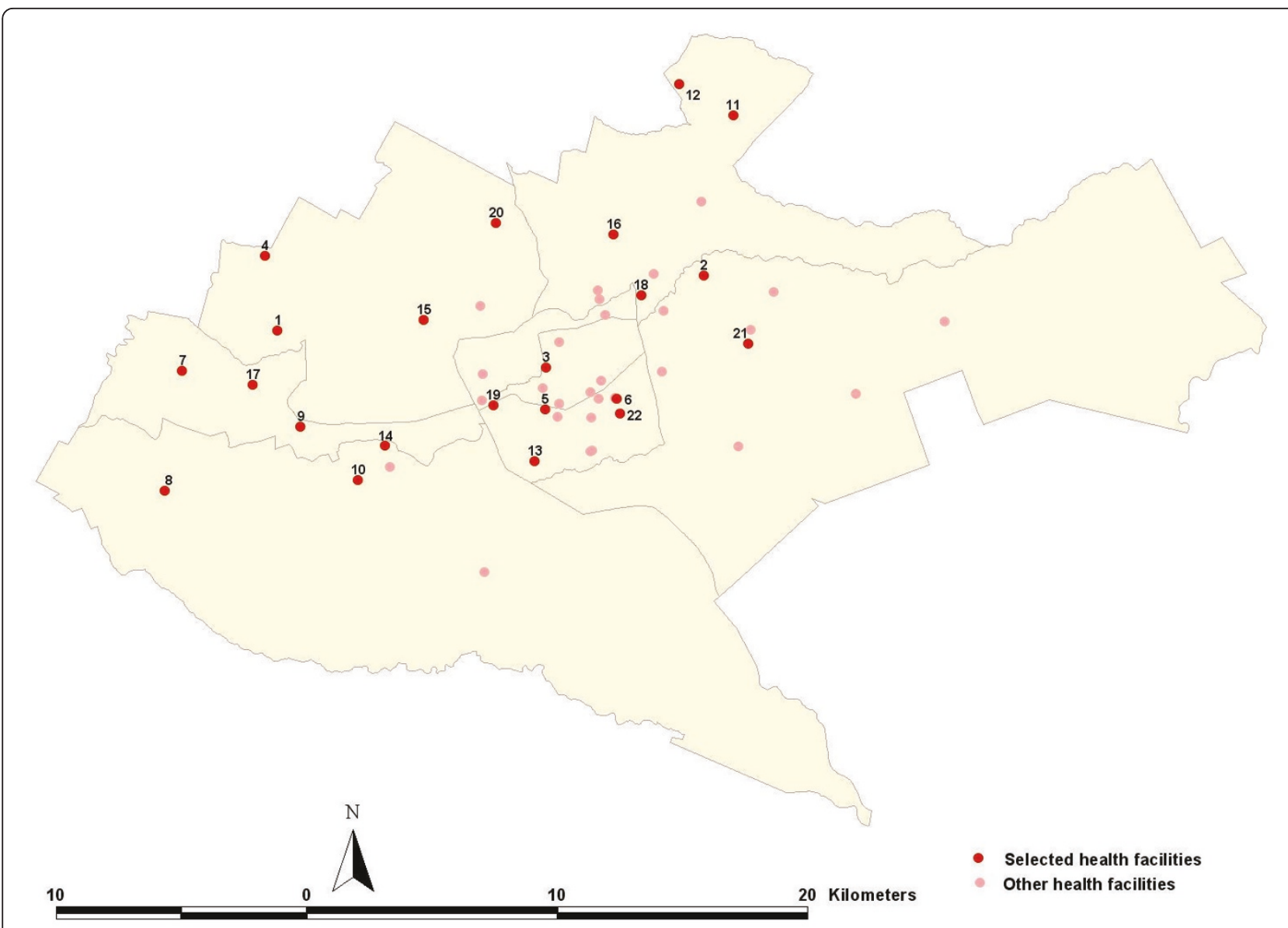

Figure 1 A division map of Nairobi showing the location of public health facilities in Nairobi. The red dot represents health facilities selected for the survey and the pink dots represent other health facilities run by MoMS or the LA in Nairobi. Surveyed facilities are as follows: 1 = Kangemi Health Centre; 2 = Dandora 2 Health Centre; $3=$ Pumwani Dispensary; $4=$ Lower Kabete; Health Centre; $5=$ Kaloleni Sub-Health Centre; 6 = Jericho Health Centre; $7=$ Waithaka Health Centre; $8=$ Karen Health Centre; $9=$ Ngong Road Health Centre; $10=$ Langata Health Centre; $11=$ Kahawa Health Centre; $12=$ Kamiti Health Centre; $13=$ Railways Training School Clinic; $14=$ Kibera DO Health Centre; $15=$ Westlands Health Centre; $16=$ Karura Health Centre; $17=$ Riruta Health Centre; 18 = Kariobangi Health Centre; $19=$ Locomotive Health Centre; 20 = Mji Wa Huruma Dispensary; 21 = Soweto/Kayole Dispensary; 22 = Makadara Health Centre.

of available attendance and laboratory records kept at the facility over the preceding 12 months to tally the monthly numbers of diagnoses made that included "malaria", those that did not include a diagnosis of "malaria", the number of diagnostic tests performed and the number reported positive among attendees. Five data collectors were recruited and trained in all survey procedures and the survey was undertaken between the $16^{\text {th }}$ August and $6^{\text {th }}$ September 2010. Data were entered from questionnaires and checked in Excel (Microsoft, USA) and analysis performed in STATA, version 11 (Stata Corp, College Station, Texas).

\section{Ethical approval}

Ethical approval was provided by the Kenyatta National Hospital/University of Nairobi Ethics and Research Committee (reference number KNH-ERC/A/383).

\section{Results}

The historical evidence of clinical malaria in Nairobi 19111960's

Malaria has been a reported clinical problem since Nairobi was first established as a colonial headquarters in 1905. Over 14,000 malaria cases were recorded in Nairobi in 1913 [38]. Malaria cases treated in government hospitals fluctuated between 2,500 and 3,600 per year between 1917 and 1919. The malaria burden remained high between 1921 and 1925 in Nairobi, with one major outbreak in 1922. For non-epidemic years 1916-1925 an average of 15.5 malaria deaths were recorded annually in government clinics across Nairobi accounting for approximately $4.1 \%$ of all hospital reported deaths across the country [38]. In 1926 [38,39], 1935 and 1940 [39,40] Nairobi suffered from malaria epidemics of substantial proportions. In 1926, more than 12,000 cases were 
treated in hospitals and health centres around Nairobi and the Medical Officer of Health reported 130 deaths due to malaria [38]. The epidemic in 1926 renewed the efforts to control malaria in Nairobi and its surveillance was improved [38]. The political concern generated by this epidemic resulted in a decision by the government to make malaria a notifiable disease in 1930 [39,41]. All medical practitioners, including those in private practices, were required by law to report all cases treated for malaria to the Medical Officer of Health. Laboratory confirmation was required for any cases deemed to be due to infections acquired locally. Malaria infections suspected to have been acquired in Nairobi were classified as 'locally acquired infections,' 'Nairobi infections,' or as 'contracted in Nairobi among residents' [41].

The malaria epidemic of 1935 followed a high incidence of malaria in 1934 (Figure 2). By the end of March 1935 there was a sudden rise in the number of cases and the epidemic reached its peak in May and then experienced a steep decline and was over by August. A total of 3,500 malaria cases were recorded, 96\% of which were among Asian or African residents who made up all of the 58 deaths recorded during this period [41]. By 1939, there were fewer cases of malaria reported and the death rate from malaria was the lowest recorded up to this point at 0.24 per 1000 persons [39]. The malaria epidemic in 1940 caused a total of 8,324 malaria cases (6,342 cases among Nairobi residents) and 62 malaria deaths [39]. The Army stationed in Nairobi was largely spared during this epidemic as strict measures had been undertaken to enforce regular compliance to the use of preventive measures and prophylactic

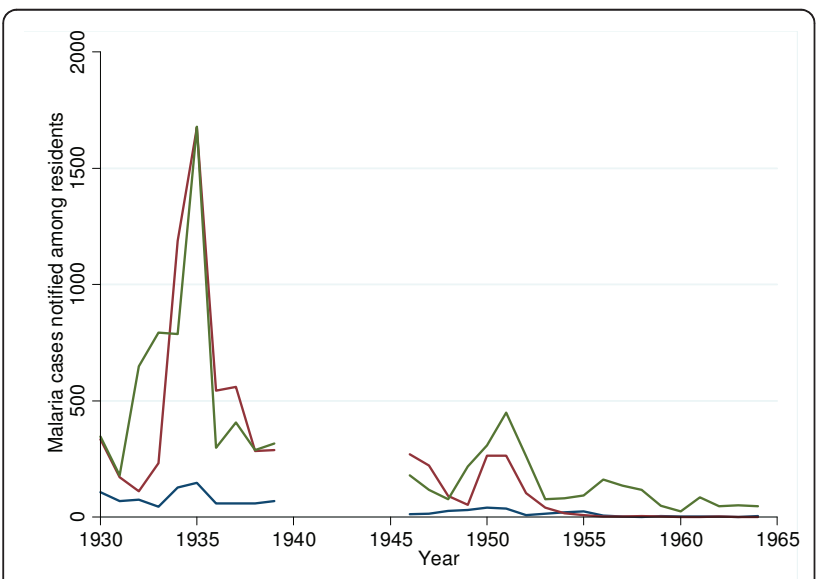

Figure 2 Malaria morbidity among residents in Nairobi between 1930 and 1964. The blue line represents malaria cases among Europeans; the red line represents cases among Asians and the green line that among Africans. (Data assembled Annual Reports of the Medical Officer of Health 1930-1964; missing 1940 1945). drugs [42]. The European population appeared to be largely unaffected by the 1940 epidemic.

Between 1930 and 1964, annual reports indicate that the period with the highest number of malaria cases occurred between March and May. This seasonal pattern of malaria was consistent throughout the reports examined. The number of malaria cases would begin to rise in February and March and the peak would occur between the months of April and July. Overall, the trend since 1911 has been of a declining incidence punctuated with epidemics. Between 1930 and 1939 malaria accounted for $3.7 \%$ of the total number of deaths in Nairobi while from 1946 to 1964 it accounted for $1.2 \%$. Notified malaria cases showed a significant decrease of autochthonous malaria from an annual average of 1,182 cases in the 1930 s, to 317 cases in the 1940 s to 250 in the 1950 s and finally 49 cases in the 1960s during a period when the numbers of Nairobi residents had increased 35 times since the 1930's [41]. Various reports suggested that aggressive control using recurrent operations such as oiling, cleaning of streams and drains, grass cutting and spraying with dichlorodiphenyltrichloroethane (DDT) may have accounted to a large extent for this decline. Malaria was perceived to be a significant public health threat and between 1950 and 1961 the Municipal Council continued to invest on average $3.9 \%$ of the total health expenditure during this period on direct vector control $[41,42]$.

\section{HMIS reports of malaria 1970-2008}

The accuracy and completeness of health information reporting on malaria across Nairobi began to decline from the 1970's and routine HMIS data are hard to locate for the city's case burdens. While it was accepted during the 1970's that transmission was possible in low lying areas of Nairobi [26] the extent of over-diagnosis of locally acquired infections became a topic of investigation. A study conducted between October 1969 and June 1970 at the Kenyatta National Hospital (KNH) among 85 patients with suspected or 'clinical' malaria found only one patient with parasitologically confirmed malaria [26]. In 1980, only $5 \%$ of adults admitted to the $\mathrm{KNH}$ with a diagnosis of malaria were finally confirmed as $P$. falciparum cases through microscopy [43].

A study of malaria out-patient diagnoses reported to the central Health Information System by public health facilities nationally showed that only $35 \%$ of expected reports between January 1996 and December 2002 were reported [44]. The Annual Health Sector Report for 2008 on the reporting rates for outpatient morbidity found Nairobi the worst with $37 \%$ for timeliness and $42 \%$ for completeness [34]. In 2007 only 3 health facilities reported any out-patient morbidity statistics. Despite the incomplete nature of the information, 
malaria remains the second most commonly diagnosed disease among attendees to out-patient clinics after respiratory tract infections between 2001 and 2008 . Malaria was reported as responsible for out-patient consultations in 10.6\% of attendances in 2001 (17,567 reported cases), 16\% in 2005 (90,214 reported cases), $18 \%$ in $2006(126,604$ reported cases $)$ and $16 \%$ in 2008 $(120,782$ cases) $[31,32,45]$.

\section{Health facility audit 2010}

Of the 22 health facilities surveyed four (18\%) were run by the MoMS and $18(82 \%)$ were run by the LA. Twenty facilities had a functioning thermometer on the day of the survey. At least one type of weighing scales was available at each facility on the day of the survey although these varied in application for different weight groups (Table 1). Current malaria policy recommends that all facilities have parasitological diagnosis either by microscopy or Rapid Diagnostic Tests (RDTs) [45]. Fifteen facilities $(68 \%)$ routinely provided microscopy; none of the facilities had RDTs; on the day of the survey only 14 facilities $(64 \%)$ had functioning microscopy services available. Eight facilities had at least one laboratory staff who had received in-service training in malaria microscopy, while six had at least one laboratory staff member who had been trained in RDT use.

Fourteen facilities (64\%) had at least one of the three widely disseminated anti-malarial drug record books (Table 1). Of those with drug records, the level of completeness was high with 12 (86\%) complete stock bin cards, 15 (88\%) complete dispenser's book and 11 (65\%) complete monthly summary forms. Fifteen facilities $68 \%$ ) had out-patient record books available on the day of the survey, however only ten (46\%) health facilities had contiguous data for the 12 months; nine (41\%) facilities had incomplete out-patient records available. Six (27\%) facilities did not have the original monthly reports at the facility and their data were retrieved from district headquarters, which keeps a copy of their data. Of the 15 facilities that had a functioning laboratory, only twelve had complete laboratory registers available for review for the preceding 12 months.

Health facilities were also assessed for availability of guidelines and wall charts that act as job aids for malaria case management. Most (68\%) facilities had the malaria guidelines prepared for health workers in 2008 [46] and the availability of the other guidelines was incomplete (Table 1). There was also a low coverage of wall charts with less than half of the facilities having any of the three wall charts that were in circulation nationally (Table 1). Nineteen health facilities had AL in stock on the survey day. Most sites had the different pack sizes available with 16 (73\%) having the 6, 18 and 24 tablet packs in stock and 18 (82\%) facilities had the 12
Table 1 Characteristics of the 22 health facilities in Nairobi (n, (\%))

\begin{tabular}{cc}
\hline Equipment and services at health facility & \\
\hline Weighing scale (any) & $21(95.5)$ \\
Infant hanging scale & $17(77.3)$ \\
Hanging Salter scale & $7(31.8)$ \\
Adult scale & $14(63.6)$ \\
Bathroom scale & $15(68.2)$ \\
\hline Thermometer & $20(90.9)$ \\
\hline Separate laboratory & $15(68.2)$ \\
\hline Functional microscopy & $14(66.7)$ \\
\hline
\end{tabular}

Record Keeping

\begin{tabular}{lc}
\hline Stock/Bin cards for AL & $14(63.6)$ \\
\hline AL dispensers book & $16(72.7)$ \\
\hline Monthly summary for malaria medicines & $16(72.7)$ \\
\hline Out-patient record books & $12(54.5)$ \\
\hline Laboratory record books & $12(54.5)$
\end{tabular}

Wall charts \& Guidelines

Malaria Guideline (Version 2) 15 (68.2)

Malaria Management chart booklet 8 (36.4)

Algorithm for $<5$ years fevers 7 (31.8)

AL dispensing and dosing schedule $12(54.6)$

Malaria OPD algorithm for older children \& adults 4 (18.2)

Integrated management of childhood illnesses chart 11 (50)

Availability of AL on the survey day

\begin{tabular}{cc}
\hline Any tablets of AL & $19(86.4)$ \\
\hline AL 6 tablets pack & $16(72.7)$ \\
\hline AL 12 tablets pack & $18(81.8)$ \\
\hline AL 18 tablets pack & $16(72.7)$ \\
\hline AL 24 tablets pack & $16(72.7)$
\end{tabular}

Stock out in last three months*

\begin{tabular}{cc}
\hline Any tablets of AL & $19(86.4)$ \\
\hline AL 6 tablets pack & $10(55.6)$ \\
\hline AL 12 tablets pack & 9 (50) \\
\hline AL 18 tablets pack & $8(44.4)$ \\
\hline AL 24 tablets pack & $7(38.9)$
\end{tabular}

Availability of other antimalarial drugs on the survey day

\begin{tabular}{lc}
\hline Availability of other antimalarial drugs on the survey day \\
\hline Amodiaquine (any formulation) & $1(4.5)$ \\
\hline Sulfadoxine-pyrimethamine (any formulation) & $14(63.6)$ \\
\hline Quinine (tablets) & $12(54.5)$ \\
\hline Quinine (injection) & $9(40.9)$ \\
\hline Artemether injection & $0(0)$ \\
\hline
\end{tabular}

*data unavailable from 4 facilities

tablet packs in stock (Table 1). Thirteen (59\%) facilities had a documented stock out of at least seven consecutive days of any of the AL packs in the past three months, May 2010 to July 2010 (Table 1).

On the day of the survey 29 out of the 31 health workers who were attending to out-patients were 
interviewed. Two health workers declined to participate. The health workers interviewed were either nurses $(23 \%)$ or clinical officers (77\%). Among the health workers, 20 (69\%) were trained in malaria case management including the use of AL. The malaria case management training was received by one health worker in 2006; two in 2008; five were trained in 2009; and 12 in 2010. The only health worker with RDT training received the training in 2009. Eighteen (62\%) health workers had access to the malaria guideline; seven (24\%) had access to the malaria management chart booklet; and 11 (38\%) had access to the Integrated Management for childhood Illnesses (IMCI) guideline. Supervision on malaria case management was low with only nine $(43 \%)$ of the health workers having had a supervisory visit in the last three months. Of those who had a supervisory visit malaria case management was the topic for nine health workers. Topics covered in the malaria case management supervision included a review of malaria records, discussion with supervisor on case management, and observed consultations in six cases (67\%), feedback was provided following $67 \%$ of supervisions.

Health workers were asked to provide a response to a series of questions related to recommended treatment regimens for malaria and the responses showed some variation between health workers in their knowledge of first line and second line recommended therapies for uncomplicated malaria (Table 2). Each of the 29 health workers was presented with a series of statements to determine their perceptions and acceptance of malaria parasite testing and treatment. Malaria parasitological testing was thought a necessary requirement of febrile patients in Nairobi by $48 \%$ of health workers and a minority $(17 \%)$ reported they would still treat for malaria even when presented with a negative diagnostic result (Table 2).

\section{Assembling the malaria case burdens at 15 clinics August 2009-July 2010}

Monthly tallies of all diagnoses were possible for all facilities; however, actual records of diagnosis were not kept at one facility (Makadara Health Centre). Retrieving the out-patient records proved time-consuming at each facility as non-current record books were scattered around the facility and for six facilities data had to be retrieved from district-level headquarters as these had not been returned to the facility. Among the 20 facilities where diagnosis-specific records were retrievable, outpatient consultations were tallied for 201 (83.8\%) of a possible 240 facility-months. At five facilities it was possible to assemble records for all 12 months, however at one facility only six months of records could be assembled (Table 3). Across the recorded months a total of 380,335 out-patient consultations were documented
Table 2 Responses to questions on recommended treatment and reported use of diagnostics by 29 health workers based in $\mathbf{2 1}$ health facilities in Nairobi

\begin{tabular}{|c|c|}
\hline $\begin{array}{l}1^{\text {st }} \text { line treatment for children below } 5 \mathrm{~kg} \text { with } \\
\text { uncomplicated malaria }\end{array}$ & $\mathrm{N}=29$ \\
\hline $\mathrm{AL}$ & $11(37.9 \%)$ \\
\hline Quinine & $15(51.7 \%)$ \\
\hline Amodiaquine & $2(6.9 \%)$ \\
\hline Don't know & $1(3.4 \%)$ \\
\hline \multicolumn{2}{|c|}{$\begin{array}{l}1^{\text {st }} \text { line treatment for children }>5 \mathrm{~kg} \text { and adults with } \\
\text { uncomplicated malaria }\end{array}$} \\
\hline $\mathrm{AL}$ & $27(93.1 \%)$ \\
\hline $\mathrm{SP}$ & $2(6.9 \%)$ \\
\hline \multicolumn{2}{|c|}{$\begin{array}{l}2^{\text {nd }} \text { line treatment for children below } 5 \mathrm{~kg} \text { and adults } \\
\text { with uncomplicated malaria }\end{array}$} \\
\hline $\mathrm{AL}$ & $4(13.8 \%)$ \\
\hline Quinine & $23(79.3 \%)$ \\
\hline DuoCotexin & $1(3.4 \%)$ \\
\hline Don't know & $2(6.9 \%)$ \\
\hline \multicolumn{2}{|c|}{$\begin{array}{l}2^{\text {nd }} \text { line treatment for children below } 5 \mathrm{~kg} \text { and adults } \\
\text { with uncomplicated malaria }\end{array}$} \\
\hline $\mathrm{AL}$ & $3(10.3 \%)$ \\
\hline SP & $1(3.4 \%)$ \\
\hline Quinine & $(44.8 \%)$ \\
\hline DuoCotexin & $2(6.9 \%)$ \\
\hline DHA-PPQ (dihydroartemisinin-piperoquine & $8(27.6 \%)$ \\
\hline Lapdap (chloroproguanil-dapsone) & $1(3.4 \%)$ \\
\hline Don't know & 1 (3.4\%) \\
\hline
\end{tabular}

Responses to questions on diagnostics - proportion

agreeing with statements

All febrile patients in Nairobi should be tested for malaria 14 (48.3\%)

Only febrile patients who recently travelled outside of 13 (44.8\%) Nairobi should be tested for malaria

Most febrile patients in Nairobi with negative RDT should 4 (13.8\%) be still treated for malaria

Most febrile patients in Nairobi with negative Blood Slide 5 (17.2\%) should be still treated for malaria

of which $37,352(9.8 \%)$ were classified as including a presumptive malaria diagnosis. Approximately equivalent proportions of out-patients aged less than five years $(8.7 \%)$ or above five years $(10.6 \%)$ were diagnosed with malaria (Table 3). The highest proportion of malaria diagnoses made amongst all age groups attending clinic between 2009-2010 was documented at the Karura Health Centre (31.6\%; Table 3; Figure 1 code 16) and the lowest documented proportion was recorded at Kibera DO Health centre (1\%; Table 3; Figure 1 code 14). Out of the 16 facilities where laboratory services were available, it was possible to assemble records for all 12 months at 10 facilities. Three facilities were missing one month of data while in the second and third facilities three and four months of data were missing 
Table 3 Record reviews August 2009-July 2010 for 21 facilities (Madakara code 22 not shown as no data available) where a diagnosis was provided in out-patient record books

\begin{tabular}{|c|c|c|c|c|c|c|c|}
\hline $\begin{array}{l}\text { Facility } \\
\text { Map code } \\
\text { (Figure 1) }\end{array}$ & $\begin{array}{c}\text { Total } \\
\text { Months } \\
\text { reviewed } \\
\text { (Missing } \\
\text { months) }\end{array}$ & $\begin{array}{l}\text { Total } \\
\text { under } 5 \\
\text { OPD } \\
\text { burden }\end{array}$ & $\begin{array}{c}\text { Total presumed } \\
\text { malaria diagnoses } \\
<5 \text { years } \\
(\% \text { of all OPD) }\end{array}$ & $\begin{array}{c}\text { Total over } 5 \\
\text { OPD } \\
\text { Burden }\end{array}$ & $\begin{array}{c}\text { Total } \\
\text { Presumed } \\
\text { Malaria } \\
\text { diagnoses }>=5 \text { years } \\
\text { (\% of all OPD) }\end{array}$ & $\begin{array}{c}\text { Total all ages } \\
\text { slides } \\
\text { performed }\end{array}$ & $\begin{array}{c}\text { Total all ages } \\
\text { Slides reported } \\
\text { positive (\%) }\end{array}$ \\
\hline $\begin{array}{l}\text { Kangemi } \\
1\end{array}$ & 12 & 8869 & $265(3.0)$ & 16117 & $639(4.0)$ & 1626 & $120(7.4)$ \\
\hline $\begin{array}{l}\text { Dandora } \\
2\end{array}$ & 12 & 10004 & $556(5.6)$ & 14548 & 769 (5.3) & 1131 & $92(8.1)$ \\
\hline $\begin{array}{l}\text { Pumwani } \\
3\end{array}$ & 11 (June) & 7139 & $1157(16.2)$ & 17101 & $2896(16.9)$ & 1209 & $204(16.9)$ \\
\hline $\begin{array}{l}\text { Lower Kabete } \\
4\end{array}$ & 12 & 5432 & $654(12.0)$ & 7051 & $997(14.1)$ & No Lab & No Lab \\
\hline Kaloleni 5 & 9 (May - July) & 5098 & $408(8.0)$ & 6804 & $1353(19.9)$ & No Lab & No Lab \\
\hline Jericho 6 & 10(Aug, Dec) & 33328 & $2140(6.4)$ & 16630 & $1942(11.7)$ & 4312 & $195(4.5)$ \\
\hline Waithaka 7 & $\begin{array}{c}8 \text { (Aug - Oct; } \\
\text { Apr) }\end{array}$ & 9985 & $427(4.3)$ & 12141 & $1248(10.3)$ & 2036 & $93(4.6)$ \\
\hline Karen 8 & $\begin{array}{c}6 \text { (Aug - Oct; Jan } \\
\text { - Mar) }\end{array}$ & 4477 & $361(8.1)$ & 9441 & $292(3.1)$ & 1404 & $359(25.6)$ \\
\hline Ngong' 9 & 9 (Aug; Jan; Feb) & 7510 & - & 11603 & $964(8.3)$ & No Lab & No Lab \\
\hline Langata 10 & 9 (Aug - Oct) & 8127 & $621(7.6)$ & 12138 & $1163(9.6)$ & 3547 & $825(23.3)$ \\
\hline Kahawa 11 & 11 (Mar) & 12861 & $1058(8.2)$ & 18631 & $1556(8.4)$ & 2488 & $105(4.2)$ \\
\hline Kamiti 12 & 9 (Aug, Feb, July) & 7475 & $679(9.1)$ & 13234 & $1393(10.5)$ & 7041 & $2213(31.4)$ \\
\hline Railway 13 & 11 (June) & 3514 & $713(20.3)$ & 4698 & $1348(28.7)$ & No Lab & No Lab \\
\hline Kibera 14 & 12 & 4947 & $36(0.7)$ & 4791 & $59(1.2)$ & 1473 & $227(15.4)$ \\
\hline Westlands 15 & $\begin{array}{c}7 \text { (Oct, Dec, May- } \\
\text { July) }\end{array}$ & 4823 & $875(18.1)$ & 9974 & 1557 (15.6) & 807 & $13(1.6 \%)$ \\
\hline Karura 16 & 12 & 3426 & $1233(36)$ & 5907 & $1600(27.1)$ & No lab & No lab \\
\hline Riruta 17 & - & - & - & - & - & 3404 & $288(8.5 \%)$ \\
\hline Kariobangi 18 & 11 (Mar) & 7713 & $1152(14.9)$ & 17241 & $1865(10.8)$ & 4592 & $601(13.1 \%)$ \\
\hline $\begin{array}{l}\text { Locomotive } \\
19\end{array}$ & 8 (Aug - Nov) & 2635 & $437(16.6)$ & 11216 & $1505(13.4)$ & 1744 & $129(7.4 \%)$ \\
\hline Huruma 20 & 11 (Feb) & 9262 & $364(3.9)$ & 7161 & $291(4.1)$ & No lab & No lab \\
\hline $\begin{array}{l}\text { Soweto/ } \\
\text { Kayole } 21\end{array}$ & 11 (Nov) & 2492 & $684(27.4)$ & - & $867(-)$ & 730 & $76(10.4)$ \\
\hline Total & 201 & 159,117 & $13,856(8.7)$ & 221,218 & $23,496(10.6)$ & 37,544 & $5,540(14.6)$ \\
\hline
\end{tabular}

respectively. Of the 37,544 blood samples sent to the 16 facilities with a laboratory, 5,540 (14.6\%) malaria blood films were recorded as positive (Table 3 ). This includes both age groups of patients and the value varied from as low as $1.6 \%$ in Westlands (Table 3; Figure 1 code 15) to $31.4 \%$ in Kamiti (Table 3; Figure 1 code 12).

\section{Discussion}

Despite unfavourable climatic conditions, Nairobi was historically an area where malaria was a common clinical problem with recurrent epidemics through to the end of the 1940s (Figure 2). Nairobi's population grew from an estimated 17,000 in 1910 [47] to approximately 300,000 by 1964 [48]. This growth brought with it changes in settlement patterns, regulations governing where people could live [49] and a growth in urban infrastructure. By the 1960s, the recorded incidence of malaria had declined significantly (Figure 2) suggesting a receptive location for transmission, but effectively controlled. The documented efforts by the city council during this period are impressive and malaria was a priority for the administration of the time, ensuring that cases were confirmed and formed part of a notifiable disease surveillance system [41]. Precisely how complete disease reporting was remains impossible to judge.

Between 1961 and 1999 Nairobi's population expanded to an estimated 2.14 million residents, living in a slightly expanded area to the boundaries of Nairobi of the 1960's. Population growth was driven by largescale national in-migration for work and sub-regional 
migrants seeking refuge from war-torn neighbouring countries. This population pressure led to the early expansion of urban slums $[49,50]$. Throughout this period very little information is available on the clinical and biological threats posed by malaria across the city. The coverage and completeness of health statistics declined and no documented evidence was available to suggest any city council or Ministry of Health allocations to malaria prevention or vector control specific to the city limits. This period probably reflects a more international decline in vertical programme interest in malaria following the abandonment of the Global Malaria Eradication Programme in Africa and the subsequent inclusion of malaria as part of general care provision through initiatives such as Primary Health Care and IMCI.

Health Information systems continued to provide challenges for the investigation of the extent and burden of malaria through to 2008. In 2007, only three health facilities reported to the Government's national HMIS. Despite the vagaries and incompleteness of the HMIS data what emerges is that malaria remains to be a very common diagnosis made at out-patient facilities across the city, second only to respiratory tract infections and contributing between $9-16 \%$ of the annual out-patient burden. To investigate the facility-level morbidity reports in more detail, records at 22 facilities were reviewed for a period of one year August 2009-July 2010. Following repeated searches and follow-up at district headquarters complete record books for 12 months were only available for 10 facilities reflecting a more basic weakness in the HMIS system beyond simply reporting to headquarters. At 21 health facilities a total of 201 months of out-patient information was available for review (Table 3). Of 159,117 paediatric diagnoses made, 13,856 (8.7\%) were recorded as malaria; among adults $10.6 \%$ of 22,496 diagnoses were recorded as malaria. These reported burdens are not dissimilar to those noted from incomplete HMIS data between 2001 and 2008 and support a general view of patients [51] and health workers [52] resident and working in Nairobi that malaria is one of the most common morbid burdens they face. As reported from a wide variety of urban settings across Africa [17-20] and in Nairobi [26,43,52], the incidence of presumed versus confirmed malaria are often very different. At 14 facilities with a functioning laboratory and available record books of microscopy the results of 37,544 slides taken during the period of review showed that $14.6 \%$ were recorded as positive, ranging from $4 \%$ to $31 \%$ between facilities with half of the surveyed facilities reporting slide positivity rates above $10 \%$. These data are hard to interpret without any sense of criteria used at each facility to request parasitological diagnosis or a measure of the accuracy of slide reading and recording. Nevertheless there is a strong suggestion that parasitologically-confirmed clinical malaria does present to health facilities in Nairobi. No documentation is ever made on travel histories, a significant risk factor for the diagnosis of malaria in Nairobi [52] and it was impossible to link records in out-patient registers to records in laboratories where these existed. This lack of detail continues to hinder reliable estimations of malaria risks in Nairobi and differs significantly in the reported efforts made during the 1930's to ensure that autochthonous versus imported slide confirmed malaria were documented for each patient [41].

Accuracy of diagnosis is key to appropriate management of fevers in low transmission settings. Efforts are underway to scale up and improve national government run health facilities' abilities to reliably diagnose malaria. However, its success will depend on adherence to test results, adequate supplies of rapid diagnostic tests where laboratories do not exist and supplies to support microscopy where this is available. Both requirements demand appropriate training and supervision and a reliable information and commodity supply chain. The findings from 22 clinics and 29 health workers indicate weaknesses in drug supply (Table 1), information communication (many records not available at the facility or a means to record data, Table 1) and adequacy of previous in-service training on nationally recommended therapies and diagnosis. If clinical malaria is to be treated as a notifiable disease to target resources and identify foci for investigation and vector control, a significant investment is required to improve the existing health system deficiencies.

Only 52 government or local authority run clinics providing malaria treatment services to Nairobi's currently estimated population of 3.14 million people [53]. As suggested from various household surveys the majority of Nairobi residents seek treatment for malaria outside the formal health care sector from private practitioners, mission and NGO run clinics and the retail sector $[27,54,55]$. Even with a functioning formal sector disease reporting and diagnostic service the use of treatment sectors outside of the formal government or LA managed sector would provide major limitations to the completeness and accuracy of a malaria notification system.

\section{Conclusions}

The possibility of locally acquired malaria infections in Nairobi remains a moot issue. Anopheles arabiensis larvae have been identified extensively across the city [Noboru Mikanawa, personal communication; 28, 56]. Studies of human infection prevalence among communities in the early 1980's [29] and school children in 2009 [57] from localities proximal to the health facilities shown in Figure 1 demonstrated P. falciparum infection prevalence between 2 and 14\%. The specific identification 
of locally acquired versus imported infections has not been established and no study has identified sporozoite positive adult vectors in the city since the 1920s [38]. As such the risks posed by local malaria transmission remain uncertain but from combined circumstantial evidence, including the reported slide positivity at 14 clinics between 2009-2010, clearly plausible. However, should transmission exist, responses to its prevention should be adapted to suit the epidemiological patterns that prevail. The promotion of universal coverage with insecticidetreated nets would be an inappropriate use of resources. A more intelligent approach to identifying, controlling and monitoring foci of transmission is probably a far better recommendation. The only entry point for this more reasoned approach to malaria prevention in Nairobi demands a rigorous case-detection system. This will require a major investment in the efficiency of HMIS, inservice training to effect a paradigm shift in how malaria is diagnosed, documented and reported across all sectors of health service provision and a response/investigation mechanism to meet the implicit needs of those who do report possible foci of transmission. While Kenya has made some progress in tackling the high disease burden across some stable endemic malaria conditions of rural communities [58] though a national strategy developed to meet the needs of these communities it will require novel innovation to tackle existing high population density, very low transmission settings such as the city of Nairobi over the next 20 years.

\footnotetext{
Acknowledgements

The authors are grateful to the support and cooperation provided by the Nairobi city council in granting access to their facilities and records and to the health workers who participated in the study. The authors acknowledge the help provided by Victor Alegana and Viola Kirui in preparing maps and locations of Nairobi health facilities; James Ang'awa, Eliud Keoro, Ellen Adhiambo, Glophas Adhiambo, Wilson Mukuna, Jeremy Mayer and Bella Okidy who helped with data collection; and lydiah Mwangi for administrative and secretarial support. SAM is supported as part of a Wellcome Trust Strategic award (\# 084538), EAO is supported by the Wellcome Trust as a Research Training Fellow (\# 086166), AMN is supported by the Wellcome Trust as a Research Training Fellow (\# 081829), DZ is supported through a Wellcome Trust project grant to Professor Snow (\# 084253) and a grant from the Medicines for Malaria Venture and RWS is supported by the Wellcome Trust as Principal Research Fellow (\# 079080)
}

\section{Author details}

Malaria Public Health \& Epidemiology Group, Centre for Geographic Medicine Research - Coast, Kenya Medical Research Institute/Wellcome Trust Research Programme, P.O. Box 43640, 00100 GPO, Nairobi, Kenya. ${ }^{2}$ Centre for Tropical Medicine, Nuffield Department of Clinical Medicine, University of Oxford, CCVTM, Oxford OX3 7LJ, UK. ${ }^{3}$ Ministry of Public Health \& Sanitation, Division of Malaria Control, P.O. Box 19982-00202, Nairobi, Kenya. ${ }^{4}$ Provincial Director of Public Health \& Sanitation Services, Ministry of Medical Services, P. O. Box 34349-00100, Nairobi, Kenya.

\section{Authors' contributions}

SAM and RWS designed the study. SAM undertook the data collection and record reviews and wrote the first draft of the manuscript. EAO, AMN and DZ provide scientific guidance at the design stage and in the analysis of the primary data. EJ and SAO provided help and stewardship in collecting the facility level data. All authors contributed to the writing and completion of the final manuscript.

\section{Competing interests}

DZ and RWS have received honoraria from Novartis Pharma for presenting and chairing, respectively, at their national malaria control programme best practice workshops in Africa. All other authors declare no competing

interests.

Received: 21 January 2011 Accepted: 20 May 2011

Published: 20 May 2011

\section{References}

1. Robert V, Macintyre K, Keating J, Trape JF, Duchemin JB, Warren M, Beier JC: Malaria transmission in urban sub-Saharan Africa. Am J Trop Med Hyg 2003, 68:169-176.

2. Keiser J, Utzinger J, Caldas de Castro $M$, Smith TA, Tanner $M$, Singer BH: Urbanization in sub-saharan Africa and implication for malaria control. Am J Trop Med Hyg 2004, 71:118-127.

3. Hay SI, Guerra CA, Tatem AJ, Atkinson PM, Snow RW: Urbanization, malaria transmission and disease burden in Africa. Nat Rev Microbiol 2005, 3:81-90.

4. Warren M, Billig P, Bendahmane DB, Wijeyaratne P: Malaria in urban and peri-urban areas in sub-Sahara Africa. August 1999 EHP activity report 71 1999 [http://www.ehproject.org], (Cited 20 May 2005).

5. Omumbo JA, Guerra CA, Hay SI, Snow RW: The influence of urbanisation on measures of Plasmodium falciparum infection prevalence in East Africa. Acta Trop 2005, 93:11-21.

6. Donnelly MJ, McCall PJ, Lengeler C, Bates I, D'Alessandro U, Barnish G Konradsen F, Klinkenberg E, Townson H, Trape JF, Hastings IM, Mutero C: Malaria and urbanization in sub-Saharan Africa. Malar J 2005, 4:12-17.

7. Kazadi W, Sexton JD, Bigonsa M, W'okanga B, Way M: Malaria in primary school children and infants in Kinshasa, Democratic republic of the Congo: surveys from the 1980s and 2000. Am J Trop Med Hyg 2004 71:97-102

8. Stoler J, Weeks JR, Getis A, Hill AG: Distance threshold for the effect of urban agriculture on the elevated self reported malaria prevalence in Accra, Ghana. Am J Trop Med Hyg 2009, 80:547-554

9. Dongus S, Nyika D, Kannady K, Mtasiwa D, Mshinda H, Gosoniu L, Drescher AW, Fillinger U, Tanner M, Killeen GF, Castro MC: Urban agriculture and Anopheles habitats in Dar es Salaam, Tanzania. Geospatial Health 2009, 3:189-210.

10. Klinkenberg E, McCall P, Wilson MD, Amerasinghe FP, Donnelly MJ: Impact of urban agriculture on malaria vectors in Accra, Ghana. Malar J 2008, 4:151.

11. Castro MC, Tsuruta A, Kanamori S, Kannady K, Mkude S: Community-based environmental management for malaria control: evidence from a smallscale intervention in Dar es Salaam, Tanzania. Malar J 2009, 8:57.

12. Keating J, Maclntyre K, Mbogo C, Githeko A, Regens JL, Swalm C, Ndenga B, Steinberg $L$, Kibe L, Githure Jl, Beier JC: A geographic sampling strategy for studying relationships between human activity and malaria vectors in urban Africa. Am J Trop Med Hyg 2003, 68:357-365.

13. Wang SJ, Lengeler C, Smith TA, Vounatsou P, Cisse G, Diallo DA, Akogbeto M, Mtasiwa D, Teklehaimanot A, Tanner M: Rapid urban malaria appraisal (RUMA) in sub-Saharan Africa. Malar J 2005, 4:40.

14. Trape JF, Zoulani A: Malaria and urbanization in central Africa: the example of Brazzaville. Part III: Relationships between urbanization and the intensity of malaria transmission. Trans R Soc Trop Med Hyg 1987, 81 S19-25.

15. Cot S, Matra R, Rabarijaona L, Robeyrt V, Raharimalala L, Raveloson A, Ariey F: (Evidence of an urban, local transmission of malaria in Antananarivo, Madagascar). Méd Trop 2006, 66:143-148.

16. Thwing JI, Mihigo J, Fernandes AP, Saute F, Ferreira C, Fortes F, de Oliveira AM, Newman RD: How much malaria occurs in urban Luanda, Angola? A health facility-based assessment. Am J Trop Med Hyg 2009, 80:487-491.

17. Wang SJ, Lengeler C, Mtasiwa D, Mshana T, Manane L, Maro G, Tanner M: Rapid Urban Malaria Appraisal (RUMA) II: epidemiology of urban malaria in Dar es Salaam (Tanzania). Malar J 2006, 5:28

18. Wang SJ, Lengeler C, Smith TA, Vounatsou P, Cisse G, Tanner M: Rapid Urban Malaria Appraisal (RUMA) III: epidemiology of urban malaria in the municipality of Yopougon (Abidjan). Malar J 2006, 5:29. 
19. Wang SJ, Lengeler C, Smith TA, Vounatsou P, Akogbeto M, Tanner M: Rapid Urban Malaria Appraisal (RUMA) IV: epidemiology of urban malaria in Cotonou (Benin). Malar J 2006, 5:45.

20. Wang SJ, Lengeler C, Smith TA, Vounatsou P, Diadie DA, Pritroipa X, Convelbo N, Kientga M, Tanner M: Rapid urban malaria appraisal (RUMA) I: epidemiology of urban malaria in Ouagadougou. Malar J 2005, 4:43.

21. UNDP: World Urbanization Prospects: The 2007 Revision. New York: United Nations 2007.

22. Hay SI, Tatem AJ, Guerra CA, Snow RW: Foresight on population at malaria risk in Africa: 2005, 2015 \& 2030. Paper prepared for UK Government's Foresight Project "Infectious Diseases: preparing for the future" 2006 [http://www.foresight.gov.uk].

23. D'Acremont $\mathrm{V}$, Lengeler $\mathrm{C}$, Mshinda $\mathrm{H}$, Mtasiwa D, Tanner M, Genton B: Time to move from presumptive malaria treatment to laboratory confirmed diagnosis and treatment in African children with fever. PLoS Med 2009, 6:252.

24. Reyburn H, Mbatia R, Drakeley C, Carneiro I, Mwakasungula E, Mwerinde O, Saganda K, Shao J, Kitua A, Olomi R, Greenwood BM, Whitty CJM: Over diagnosis of malaria in patients with severe febrile illness in Tanzania: a prospective study. BMJ 2004, 329:1212-1217.

25. Rogers DJ, Randolph SE, Snow RW, Hay SI: Satellite imagery in the study and forecast of malaria. Nature 2002, 415:710-715.

26. Rees PH, Touquet VL, Allen AV, Nyawade ZN: "Clinical malaria" in Nairobi. East Afr Med J 1971, 48:51-55.

27. Yé $Y$, Madise N, Ndugwa R, Snow RW: Fever treatment in the absence of malaria transmission in an urban informal settlement in Nairobi, Kenya. Malar J 2009, 8:160.

28. Kasili S, Odemba N, Ngere FG, Kamanza JB, Muema AM, Kutima HL: Entomological assessment of the potential for malaria transmission in Kibera slum of Nairobi, Kenya. J Vector Borne Dis 2009, 46:273-279.

29. Rapuoda B, Achola P: Study on malaria and its vectors in Nairobi: A review of the distribution of the vectors and the prevalence of the disease. KEMRI/KETRI 5th Annual Medical Scientific Conference, Nairobi, Kenya 1984, 115-119

30. Njeru C: Malaria parasite thriving better in warmer city. Daily Nation 2009, 2.

31. Ministry of Health: Annual Health Sector Statistics Report 2001-2004. Republic of Kenya, Nairobi; 2004.

32. Ministry of Health: Annual Health Sector Statistics Report 2005-2007. Republic of Kenya, Nairobi; 2007.

33. Ministry of Medical Services \& Ministry of Public Health and Sanitation: Strategic Plan for Health Management Information Systems, 2009-2014. Republic of Kenya, Nairobi 2009.

34. Ministry of Public Health and Sanitation: Annual Health Sector Statistics Report 2008. Division of Health Management Information Systems, Nairobi 2009.

35. Noor AM, Alegana VA, Gething PW, Snow RW: A spatial national health facility database for public health sector planning in Kenya in 2008. International Journal of Health Geographics 2009, 8:e13.

36. Juma $E$, Zurovac $D$ : Changes in health workers adherence to diagnosis and treatment guidelines in Kenya. Mal J 2011, 10:1.

37. DOMC: Monitoring outpatient malaria case management under the 2010 diagnostic and treatment policy in Kenya-baseline results. Division of Malaria Control, Ministry of Public Health and Sanitation, Nairobi 2010.

38. Symes CB: Malaria in Nairobi. East Afr Med J 1940, 17:332-355.

39. De Mello JP: Some aspects of Malaria in Kenya. East Afr Med J 1947, 24:112-123.

40. Haynes WS: The malaria epidemic. East Afr Med J 1940, 17:216-221.

41. Nairobi Municipality, Kenya: Medical and Sanitation Department Annual Reports. Government of Kenya , (1930-39; 1946-65; 1967).

42. Colony \& Protectorate of Kenya: Medical and Sanitation Department Annual Reports. Government of Kenya , (1911-1912; 1926-27; 1940-41; 149; 1951).

43. Bhatt KM, Omani JM, Kyobe J, Kanja C: Clinical malaria in Nairobi. East Afr Med J 1984, 61:303-305.

44. Gething PW, Noor AM, Gikandi PW, Ogara EA, Hay SI, Nixon MS, Snow RW, Atkinson PM: Improving imperfect data from health management information systems in Africa using space-time geostatistics. PLOS Med 2006, 3:e271.

45. Ministry of Public Health and Sanitation: National Malaria Strategy 20092017. Ministry of Public Health and Sanitation, Division of Malaria Control, Nairobi 2009.
46. Ministry of Health: National guidelines for diagnosis, treatment and prevention of malaria for health workers. Ministry of Health, Division of Malaria Control, Nairobi 2008.

47. Kuczinsky C: Demographic survey of the British Colonial Empire. Augustus M. Kelley Publisher, London; 1949, 126-229.

48. Obudho RA, Aduwo A: The nature of the urbanisation process and urbanism in the city of Nairobi, Kenya. African Urban Quarterly 1992, 7(1 \& 2).

49. Muwonge JW: Urban policy and patterns of low-income settlement in Nairobi, Kenya. Population and Development Review 1980, 6:595-613.

50. Macharia K: Slum clearance and the informal economy in Nairobi. Journal of Modern African Studies 1992, 30:221-236.

51. Yé Y, Kimani-Murage E, Kebaso J, Mugisha F: Assessing the risk of selfdiagnosed malaria in urban informal settlements of Nairobi using selfreported morbidity survey. Mal J 2007, 6:71.

52. MSF - France: Evaluation of malaria case management and most common children illnesses in UPENDO dispensary: operational implications on general improvement of care. Nairobi, MSF-France, unpublished report 2002.

53. Kenya National Bureau of Statistics: Kenya National Population and Housing Census 2009. Ministry of Planning, Nairobi 2010.

54. Taffa N, Chepngeno G: Determinants of health care seeking for childhood illnesses in Nairobi slums. Tropical Medicine and International Health 2005, 10:240-245.

55. Kenya Demographic and Health Survey 2008-9: [http://www.measuredhs. com/pubs/pdf/FR229/FR229.pdf], Accessed 16 January 2010.

56. Okara RM, Sinka ME, Minakawa N, Mbogo CM, Hay SI, Snow RW: Distribution of the main malaria vectors in Kenya. Mal J 2010, 9:69.

57. Gitonga CW, Karanja PN, Kihara J, Mwjame M, Juma E, Snow RW, Noor AM, Brooker S: Implementing school malaria surveys in Kenya: towards a nationwide surveillance system. Malar J 2010, 9:306.

58. Okiro EA, Alegana VA, Noor AM, Mutheu JJ, Juma E, Snow RW: Malaria hospitalization between 1999 and 2008 across Kenya. BMC Med 2009, 7 e75.

doi:10.1186/1475-2875-10-138

Cite this article as: Mudhune et al:: The clinical burden of malaria in Nairobi: a historical review and contemporary audit. Malaria Journal 2011 10:138.

\section{Submit your next manuscript to BioMed Central and take full advantage of:}

- Convenient online submission

- Thorough peer review

- No space constraints or color figure charges

- Immediate publication on acceptance

- Inclusion in PubMed, CAS, Scopus and Google Scholar

- Research which is freely available for redistribution

Submit your manuscript at www.biomedcentral.com/submit
Ciomed Central 